\title{
SYNTHESIS AND CHARACTERIZATION OF POLYMERIC MATERIAL BLENDED WITH VARYING Zn AND C NANOPARTICLES
}

\author{
Obasi, Ibe. B. \\ Department of Physics/Electronics \\ Federal Polytechnic, Nekede, Owerri, Nigeria
}

\author{
Asiegbu, Daniel. A. \\ Department of Physiscs \\ Michael Okpala University of Agriculture Umudike, \\ Nigeria
}

\author{
Nnanna, Lebe \\ Department of Physiscs \\ Michael Okpala University of Agriculture Umudike, Nigeria
}

\begin{abstract}
This study experimentally investigated the addition of zinc $(\mathrm{Zn})$ and graphite $(\mathrm{C})$ nanomaterial into polymeric material by sol-gel technique. The objectives of this paper were to outline our investigations in the evolving process of dispersing nanoparticles into polyvinyl alcohol, propylene glycol and methyl cellulose (PVA/PG/MC) polymeric matrix, to study their versatile properties, and evaluating its performance for different applications. The morphology features and chemical composition of the solgel prepared PVA/PG/MC hybrid polymer loaded with Zn and $C$ of varying mixture deposited on metal substrates samples were studied using scanning electron microscopy (SEM) image analysis and the Fourier Transform Infrared (FTIR). The treatment of the nanoparticles of varying quantities used as inorganic materials in PVA/PG/MC polymeric material, has resulted in the polymeric nanostructured materials presenting high performance and multipurpose characteristics beyond that of the parent material original properties. Improved versatile features attributed to the as-synthesized polymeric are materials resistance to moisture, and sterile properties. Furthermore, the study showed that the $\mathrm{Zn}$ and $\mathrm{C}$ nanoparticles of equal mass ratio were uniformly dispersed in the polymeric material as the particles retained their original size before blending into the polymeric material. This study shows the prospect of applying these nanoparticles as tones with antibacterial properties in several applications.
\end{abstract}

Keywords: Nanoparticle, PVA/PG/MC, Zn:C nanocomposite, polymeric material, SEM, FTIR

\section{INTRODUCTION}

Composites at the nanoscale are materials of distinct class that have unique properties and wide application potential in various areas and emphasized in literature by Wu et al. (2015) and Aziz et al. (2019). Ayazi (2017), described the unique properties of nanocomposites can be achieved by successfully joining features of parent constituents into a single material as well as Mohanapriya et al. (2016). These polymeric materials are of different constituents and possesses diverse physical and chemical properties. The addition of nanosized $\mathrm{Zn}$ and $\mathrm{C}$ inorganic particles into the polymeric media constitutes the new composites material that will exhibit unexpected properties, which significantly differ from that of parent materials.

The strong tendency for nanoparticles to agglomerate results to difficulty in the retention of homogeneous dispersion of nanosized particle in the preparation process of nanocomposites, as represented in literatures by Senthil and Gunasundari (2018); Baig, et al. (2018) and Fakirov (2020). To overcome formation of agglomerated nanoparticles in polymers, the blending of inorganic particles into polymer matrixes is generally achieved by surface modification Akindoyo et al., (2017); Surface modification of nanoparticles by the phase transfer of the particles (Milne et al., 2018), bioinspired chemical approach (Ata et al., 2014). and grafting polymerization (Choi, et al.,2006) are all effective ways to improve its dispersion in polymeric matrix, and hence improve the polymeric matrix, thus improving the properties of the resulting composites. $\mathrm{Zn}$ and $\mathrm{C}$ nanoparticles are multiuse inorganic nanoparticles that has shown increasing, attention in literature because of its many significant physical and chemical stability (Estrada-Guel et al., 2009), high catalysis activity (Bedi and Kaur, 2015), effective antibacterial and bactericide function (Rajendra, et al., 2010), intensive ultraviolet and infrared adsorption (Guardia et al., 2012).

Furthermore, the development of $\mathrm{Zn}$ and $\mathrm{C}$ nanoparticles could increase the properties of polymer matrix (Kango et al, 2013). However, $\mathrm{Zn}$ and $\mathrm{C}$ nanoparticles, like other nanoparticles, have high surface energy, which could be dispersed in organic solvent and matrix. Subsequently, it is required to prepare $\mathrm{Zn}: \mathrm{C} /$ polymeric nanocomposites devoid of the creation of agglomerated nanoparticles. The nanocomposites can progress the dispersion stability of $\mathrm{Zn}$ and $\mathrm{C}$ and improve adhesion 
between the polymeric material and varied mixture of $\mathrm{Zn}: \mathrm{C}$ nanoparticles.

In this paper, we present the synthesis and properties of $\mathrm{PVA} / \mathrm{PG} / \mathrm{MC}$ polymeric material blended with varying mixing ratio of $\mathrm{Zn}$ and $\mathrm{C}$ powders and explore the possibility enhanced properties into polymer matrix.

\section{MATERIALS AND METHOD}

\section{A. Materials}

The materials used are $99 \%$ hydrolyzed commercial-grade polyvinyl alcohol (PVA) with a weight-average molecular weight of $124,000 \mathrm{~g} / \mathrm{mol}$, propylene glycol (PG) with a molecular weight of $76.10 \mathrm{~g} / \mathrm{mol}$, and methyl cellulose (MC) with a molecular weight of $454 \mathrm{~g} / \mathrm{mol}$, were acquired from Sigma-Aldrich was used in this study.

\section{B. Preparation PVA/PG/MC polymeric material blended with $\mathrm{Zn}$ : $\mathrm{C}$ of varying proportions}

100 grams of polyvinyl alcohol (PVA) was dissolved in 1 liter of water by sprinkling into the water heated to $80^{\circ} \mathrm{C}$ while stirring continuously using a magnetic stirrer equipped with hot plate for 20 minutes, was stirred until the solution was clear. Again, $30 \mathrm{~g}$ of methyl cellulose was dissolved similarly like the PVA solution, after $15 \mathrm{~min}$, the solution was allowed to cool at ambient temperature and stored at around $4^{\circ} \mathrm{C}$ for $24 \mathrm{~h}$ before use. The propylene glycol was used as received without any modification. These solutions (PVA/PG/MC) denoted as H0 were mixed together to form the polymeric matrix in a ratio of $4: 1: 2$ in that order, the mixtures were agitated thoroughly to form a homogenous mixture.

Secondly, varying weight proportions of zinc and graphite powders were mixed into the primary solution (PVA/MC/PG). Four samples of the nanoparticle were prepared with different mixing ratios of zinc and graphite with this primary polymeric solution. The zinc and graphite powders $(\mathrm{Zn}: \mathrm{C})$ mixture were as follows: $45 \mathrm{~g}: 15 \mathrm{~g}, 36 \mathrm{~g}: 24 \mathrm{~g}$, and $30 \mathrm{~g}: 30 \mathrm{~g}$, these mixtures were dispersed in $100 \mathrm{ml}$ ethanol in ethanol and finally mixing $10 \mathrm{ml}$ of each with $40 \mathrm{ml}$ of the polymeric solution to produce three new solutions denoted as (H1-H3) in addition to the $\mathrm{H} 0$ primary hybrid solution totaling six polymeric systems. These mixtures were allowed to settle for few minutes and applied on a metal substrate by the dip-coating method that serves as sample holder and lastly, dried in a drying at oven temperature of $80^{\circ} \mathrm{C}$.

\section{Characterization of $\mathrm{Zn}: \mathrm{C}$ Nano powders blended with polymeric material}

The morphology of the polymeric material, respectively the dispersion morphology of $\mathrm{Zn}$ and $\mathrm{C}$ particles in polymeric matrix was observed by using SEM. A Fourier Transform Infrared Spectrophotometer (FTIR) analysis was used to characterize the functional groups of the $\mathrm{Zn}: \mathrm{C}$ nanoparticles blended with PVA/PG/MC polymeric materials.

\section{RESULTS AND DISCUSSIONS}

\section{A. Morphology of Samples Ho - H3}

The morphology of samples H0 - H3 SEM images are presented in Fig.1. This figure presented SEM images of $\mathrm{Zn}: \mathrm{C}: \mathrm{PVA} / \mathrm{PG} / \mathrm{MC}$ hybrid structure samples. The morphology of the particles is granular and the particles are loosely agglomerated. It can be seen that indifferent types of $\mathrm{Zn}$ and $\mathrm{C}$ nanoparticles are well dispersed in polymer matrix. Matei et al. (2008) attributed this fact shown as a manifest of good adhesion between the surface of nanoparticles and PVA/PG/MC matrix has been established by the organic surface modification of the $\mathrm{Zn}$ :C nanoparticles.

The size and distribution of $\mathrm{Zn}: \mathrm{C}$ nanoparticles in polymer matrix were also confirmed using SEM (David and Petr, 2012), as shown in Fig. 2. The sizes of HO nanoparticles are in the range of $420-520 \mathrm{~nm}$. The particle distribution of $\mathrm{H} 1-\mathrm{H} 3$ are in the range of $100-800 \mathrm{~nm}$, the difference in their size distribution begin due to $\mathrm{Zn}$ and $\mathrm{C}$ powders content. In case of $\mathrm{H} 0$ the size of nanoparticles has a tendency of limited size range. For $\mathrm{H} 1-\mathrm{H} 3$ samples, the distribution of particles reflects similar microgranular structures as the $\mathrm{Zn}$ and $\mathrm{C}$ content varied. Table 1. Presents some statistical parameters from the grain particle distribution of the as-synthesized hybrid structures. Also, Fig. 2 supports a very narrow size distribution of $\mathrm{H} 3$ particles, towards the lower sizes at equal $\mathrm{Zn}$ and $\mathrm{C}$ particle addition.

As it's obvious from Table 1, the estimated crystallite size on the area and volume increased with addition of nanoparticles this consequent of the crystal growth and combination of nanoparticles. Increase in the degree of weighted ratio of $\mathrm{Zn}$ and $\mathrm{C}$ led to improving surface smoothness which is obvious from the declining roughness value and maximum peak height. These samples were tried as antibacterial agents. PVA/PG/MC treated with $\mathrm{Zn}$ and $\mathrm{C}$ of equal ration displayed the best antibacterial activity. It was shown that the concentration of $\mathrm{Zn}$ and $\mathrm{C}$ acted considerably in the inhibitory effect on bacteria's. Furthermore, the nanocomposite films showed that the best performing asprepared sample maintained their properties after dispersion in polymeric medium. 
International Journal of Engineering Applied Sciences and Technology, 2020

Vol. 5, Issue 2, ISSN No. 2455-2143, Pages 621-625

Published Online June 2020 in IJEAST (http://www.ijeast.com)

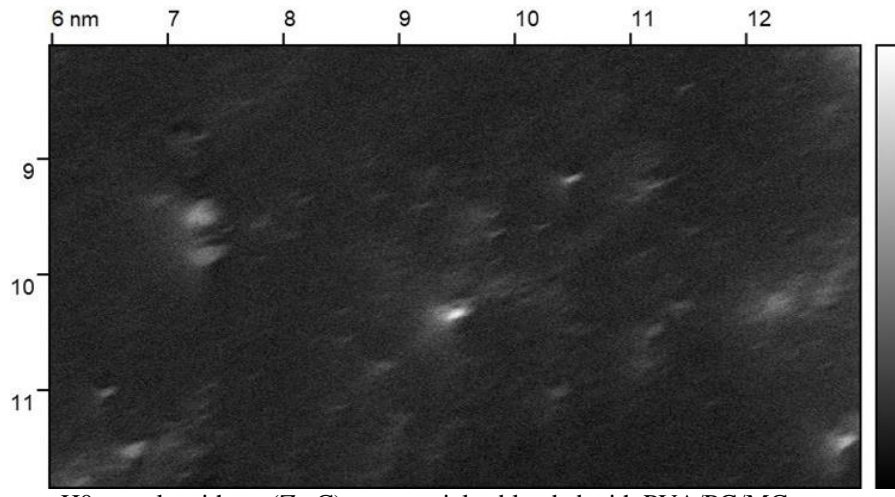

H0 sample without (Zn:C) nanoparticles blended with PVA/PG/MC polymeric hybrid structure

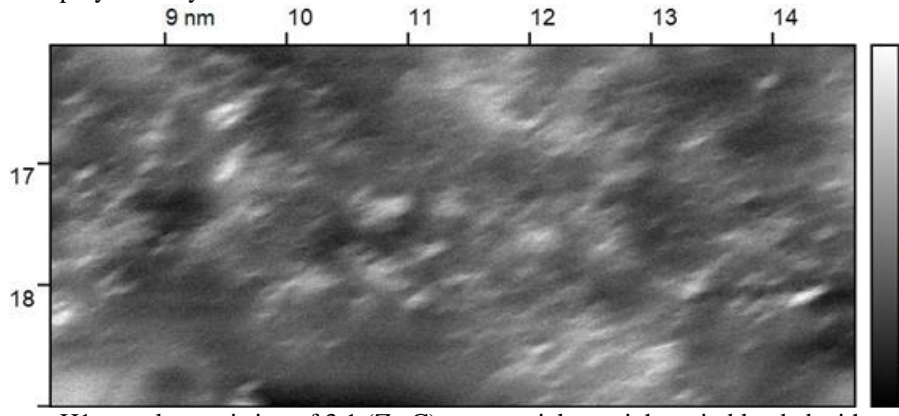

H1 sample consisting of 3:1 ( $\mathrm{Zn:C})$ nanoparticles weight ratio blended with

PVA/PG/MC polymeric hybrid structure

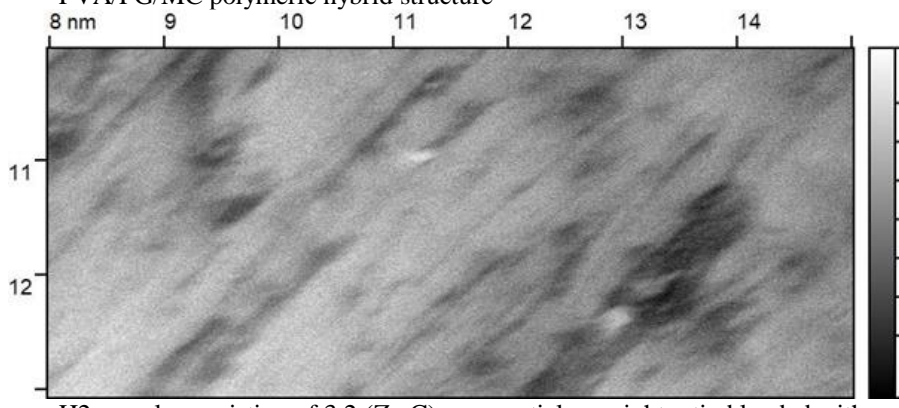

H2 sample consisting of 3:2 (Zn:C) nanoparticles weight ratio blended with $\mathrm{PVA} / \mathrm{PG} / \mathrm{MC}$ polymeric hybrid structure

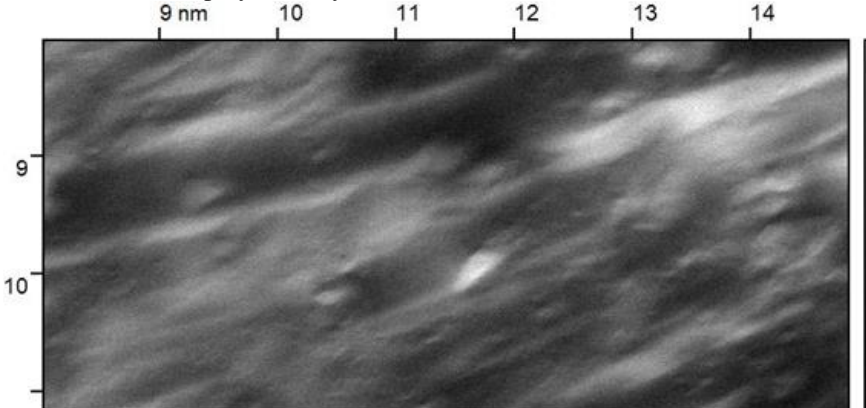

H3 sample consisting of 1:1 (Zn:C) nanoparticles weight ratio blended with $\mathrm{PVA} / \mathrm{PG} / \mathrm{MC}$ polymeric hybrid structure

Fig. 1 SEM images of the as-synthesized polymeric material blended with varying $\mathrm{Zn}$ and $\mathrm{C}$ nanoparticles
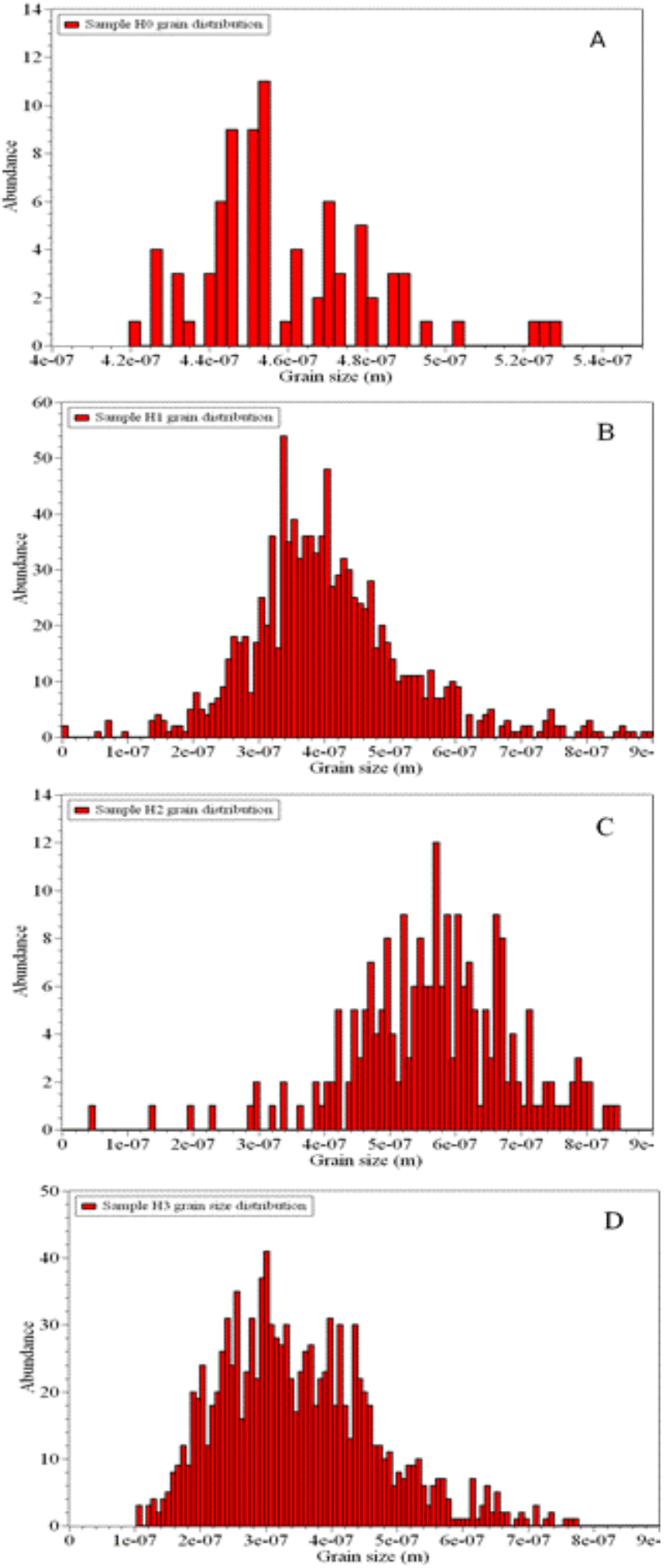

Fig. 2. Grain distribution analysis of the as-synthesized (a) PVA/PG/MC polymeric structure only, (b) treated with 3:1 ratio (c) treated with 3:2 ratio and (d) treated with 1:1 ratio, of zinc and graphite nanoparticles. 
Table 1. Statistical grain distribution parameters and film thickness

\begin{tabular}{|l|l|l|l|l|}
\hline \multirow{2}{*}{ Grain parameter } & \multicolumn{3}{|l|}{ Sample ID } \\
\cline { 2 - 5 } & H0 & H1 & H2 & H3 \\
\hline Average value $(\mu \mathrm{m})$ & 0.34 & 0.53 & 0.65 & 0.5 \\
\hline Mean roughness $(\mu \mathrm{m})$ & 0.28 & 0.23 & 0.18 & 0.25 \\
\hline Skew $($ Ssk $)$ & 1.34 & 0.69 & -0.13 & 0.69 \\
\hline Median $(\mu \mathrm{m})$ & 0.18 & 0.42 & 0.62 & 0.4 \\
\hline Max peak height $(\mu \mathrm{m})$ & 0.66 & 0.47 & 0.35 & 0.5 \\
\hline Max pit depth $(\mu \mathrm{m})$ & 0.34 & 0.53 & 0.65 & 0.5 \\
\hline Projected area $\left(\mathrm{nm}^{2}\right)$ & 197 & 165 & 161 & 171 \\
\hline Surface area $\left(10^{5} \mathrm{~nm}^{2}\right)$ & 4.35 & 3.09 & 4.63 & 2.99 \\
\hline Volume $\left(10^{4} \mathrm{~nm}^{2}\right)$ & 6.71 & 8.69 & 10.5 & 8.54 \\
\hline Inclination $\theta(\mathrm{deg})$ & 7.24 & 9.35 & 6.19 & 8.95 \\
\hline Scan line discrepancy & 0.12 & 0.1 & 0.11 & 0.09 \\
\hline Film thickness $(\mu \mathrm{m})$ & 12.3 & 16.33 & 14.91 & 14.23 \\
\hline
\end{tabular}

\section{B. $\quad$ FTIR analysis of samples $\mathrm{HO}-\mathrm{H3}$}

The FTIR spectra of the samples are shown in Fig.3. From the results obtained, it can be seen that the FTIR revealed more than five peaks, informing that the analyzed is not a simple chemical (Coates, 2000). Wave numbers deduced from the FTIR spectrum of the samples as well as the assignment of vibration type and functional groups are presented in Tables 2 and 3 respectively. There were $\mathrm{C}-\mathrm{C}$ bond, hydrogen bond and the material exhibits an aromatic structure as seen in this result. The material depicted no triple bond region (2000-2500 $\left.\mathrm{cm}^{-1}\right)$, informing no $\mathrm{C} \equiv \mathrm{C}$ bond in the material. The huge and sharp peak detected at about $1700 \mathrm{~cm}-1$. This informs some carbonyl double bond. Table 2 depicted that $\mathrm{HO}$ - H3 samples consists of $\mathrm{O}-\mathrm{H}$ stretch phenolic alcohol at $3350 \mathrm{~cm}^{-1}$. There is $\mathrm{C}=\mathrm{O}$ stretching of saturated aliphatic aldehyde at $1717 \mathrm{~cm}^{-1}$. There are $\mathrm{O}-\mathrm{H}$ stretching of carboxylic acids at $2916 \mathrm{~cm}^{-1}$. Inclusive is the $\mathrm{C}-\mathrm{H}$ rock alkanes at $1241 \mathrm{~cm}^{-1}$ and $\mathrm{C}-\mathrm{H}$ loop of aromatic at $843 \mathrm{~cm}^{-1}$. In addition, $\mathrm{C}-\mathrm{H}$ wag alkyl halides and $\mathrm{C}-\mathrm{N}$ stretching of aliphatic amines similarly occurred at the range of $1029 \mathrm{~cm}^{-1}-1100 \mathrm{~cm}^{-1}$, respectively.

Table 2. Wave numbers deduced from the FTIR spectrum of $\mathrm{H} 0-\mathrm{H} 3$ samples and assignment functional groups

\begin{tabular}{|l|l|}
\hline Wave No & Assigned functional group \\
\hline 843 & aromatic \\
\hline 1029 & stretch, aliphatic amines \\
\hline 1100 & wag, alkyl halide \\
\hline 1241 & rock, alkanes \\
\hline 1717 & stretch, aldehyde, saturated \\
\hline 2916 & stretch, carboxylic acid \\
\hline 3350 & stretch, alcohol, phenol \\
\hline
\end{tabular}

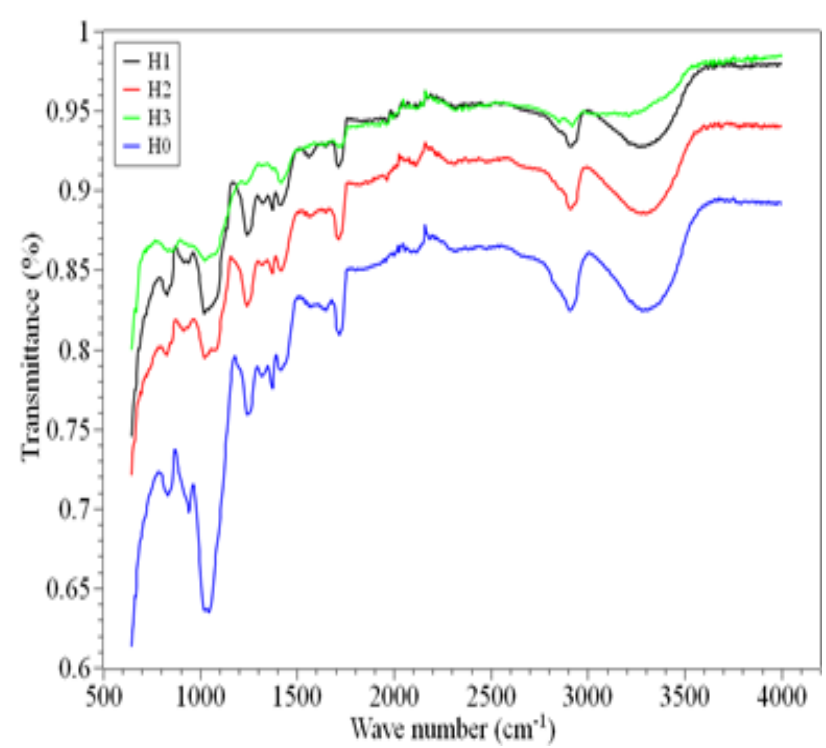

Fig. 3. FTIR spectra of the samples $\mathrm{H} 0-\mathrm{H} 3$

\section{CONCLUSION}

Polymeric composite films of PVA/PG/MC mixed with zinc and graphite nanoparticles were prepared by a low costeffective sol-gel technique. The effect of the varying zinc and graphite ratio in the hybrid polymer on the morphology and, composition of the polymeric structure particles were investigated and discussed through SEM and FTIR analysis. SEM studies show the varying formation of randomly and closely packed grain particles with distinctive arrangement and morphology of the particle can be controlled by varying the nanoparticles. Microstructure parameters area and volume averaged crystal size, mean roughness were achieved using Gwyddion. The results show that the as-deposited films exhibited considerable sterile capability particularly after adding the $\mathrm{Zn}: \mathrm{C}$ of equal weight ration treated in the hybrid polymeric structure, hence presenting it as a multipurpose material.

\section{REFERENCES}

[1] Akindoyo, J. O., Beg, M. D., Ghazali, S., Heim, H. P., \& Feldmann, M. (2017). Effects of surface modification on dispersion, mechanical, thermal and dynamic mechanical properties of injection molded PLA-hydroxyapatite composites. Composites Part A: Applied Science and Manufacturing, 103, (pp. 96-105).

[2] Ata, M.S. Liua, Y. \& Zhitomirsky, I. (2014). A review of new methods of surface chemical modification, dispersion and electrophoretic deposition of metal oxide particles, RSC Advances (4) (pp. 22716-22732). DOI.10.1039/C4RA02218A.

[3] Ayazi, Z. (2017). Application of nanocomposite-based sorbents in microextraction techniques: a review. Analyst, 142(5), (pp. 721-739). 
[4] Aziz, S. B., Hassan, A. Q., Mohammed, S. J., Karim, W. O., FZ Kadir, M., A Tajuddin, H., \& NMY Chan, N. (2019). Structural and optical characteristics of PVA: CDot composites: Tuning the absorption of ultra violet (UV) region. Nanomaterials, 9(2), (pp. 21-26).

[5] Baig, Z., Mamat, O., \& Mustapha, M. (2018). Recent progress on the dispersion and the strengthening effect of carbon nanotubes and graphene-reinforced metal nanocomposites: a review. Critical Reviews in Solid State and Materials Sciences, 43(1), (pp. 1-46).

[6] Bedi, P., \& Kaur, A. (2015). An overview on uses of zinc oxide nanoparticles. World Journal of Pharmacy and Pharmaceutical Sciences, 4(12), (pp. 1177-1196).

[7] Choi, H. W., Lee, H. J., Kim, K. J., Kim, H. M., \& Lee, S. C. (2006). Surface modification of hydroxyapatite nanocrystals by grafting polymers containing phosphonic acid groups. Journal of colloid and interface science, 304(1), (pp. 277-281).

[8] David N., \& Petr K., (2012). Gwyddion: An open-source software for SPM data analysis, Central Eupean. Journal of Physics, 10(1) (pp. 181-188).

[9] Estrada-Guel, I., Carreño-Gallardo, C., Mendoza-Ruiz, D. C., Miki-Yoshida, M., Rocha-Rangel, E., \& MartínezSánchez, R. (2009). Graphite nanoparticle dispersion in 7075 aluminum alloy by means of mechanical alloying. Journal of Alloys and Compounds, 483(1-2), (pp. 173177).

[10] Fakirov, S. (2020). Polymer nanocomposites: Why their mechanical performance does not justify the expectation and a possible solution to the problem? Express Polymer Letters, 14(5), (pp. 436-466).

[11] Guardia, L., Villar-Rodil, S., Paredes, J. I., Rozada, R., Martínez-Alonso, A., \& Tascón, J. M. D. (2012). UV light exposure of aqueous graphene oxide suspensions to promote their direct reduction, formation of graphenemetal nanoparticle hybrids and dye degradation. Carbon, 50(3), (pp. 1014-1024).

[12] Kango, S., Kalia, S., Celli, A., Njuguna, J., Habibi, Y., \& Kumar, R. (2013). Surface modification of inorganic nanoparticles for development of organic-inorganic nanocomposites-A review. Progress in Polymer Science, 38(8), (pp. 1232-1261).

[13] Matei, A., Cernica, I., Cadar, O., Roman,C. \& Schiopu, V. (2008). Synthesis and characterization of $\mathrm{ZnO}$ - polymer nanocomposites, International Journal of Mater Form (1) (pp. 767-770). DOI 10.1007/s12289-008-0-2885.

[14] Milne J, Ricardo, M.S, Igor, Z. (2018). Surface modification and dispersion of ceramic particles using liquid-liquid extraction method for application in supercapacitor electrodes. Journal of the European Society, 30(12), (pp. 3450-3455).

[15] Mohanapriya, M. K., Deshmukh, K., Ahamed, M. B., Chidambaram, K., \& Pasha, S. K. (2016). Zeolite 4A filled poly (3, ethylenedioxythiophene):(polystyrenesulfonate)(PEDOT:
PSS) and poly (vinyl alcohol)(PVA) blend nanocomposites as high-k dielectric materials for embedded capacitor applications. Adanced. Material Letter 7(12), (pp. 996-1002).

[16] Rajendra, R., Balakumar, C., Ahammed, H. A. M., Jayakumar, S., Vaideki, K., \& Rajesh, E. (2010). Use of zinc oxide nano particles for production of antimicrobial textiles. International Journal of Engineering, Science and Technology, 2(1), (pp. 202-208).

[17] Senthil Kumar, P., \& Gunasundari, E. (2018). Nanocomposites: Recent Trends and Engineering Applications. In Nano Hybrids and Composites 20, (pp. 65-80)

[18] Wu, R., Zhou, K., Yue, C. Y., Wei, J., \& Pan, Y. (2015). Recent progress in synthesis, properties and potential applications of $\mathrm{SiC}$ nanomaterials. Progress in Materials Science, 72, (pp. 1-60).

[19] Yadav, Tapesh (2005). "Zinc comprising nanoparticles and related nanotechnology." U.S. Patent Application No. $10 / 780,671$ 